\title{
A análise situacional de Karl Popper: alguma analogia com a lógica da situação na economia? ${ }^{1}$
}

\author{
Solange Regina Marin ${ }^{2}$
}

\section{Resumo}

A contribuição metodológica de Popper se estende para a aplicação do seu método crítico nas práticas científicas e sociais, ou seja, vai além do falsificacionismo e do diálogo socrático como mostrado nas diferentes interpretações dos metodólogos da economia. Com o objetivo de descrever a prática científica e social de Popper, como resultado de sua ênfase na busca e no crescimento do conhecimento, e investigar se existe alguma analogia entre ela e a lógica da situação na economia, este artigo apresenta: i) a prática científico-social popperiana na forma da análise situacional (seção 1), ii) as discussões de alguns críticos e comentadores que identificam problemas na proposta de Popper (seção 2), iii) argumentos sobre a análise situacional de Popper e a lógica da situação na economia (seção 3) e iv) as considerações finais.

Palavras-chave: Popper, Karl; Análise situacional; Economia.

\begin{abstract}
Karl Popper's social analysis: some analogy with the logic of situation in economics? -

Popper's methodological contribution could be extended in order to include the use of his critical method in social and scientific practices, that is, it is not related only to falsificationism and socratic dialogue as it has been presented by different economic methodologists. With the aim of describing Popper's social and scientific practice, as a result of his emphasis on search and growth of knowledge, and investigating whether exists some analogy between this practice and the logic of situation in Economics, this paper presents: i) Popper's social-scientific practice represented by his situational analysis (section 1), ii) discussions of some researchers who identify problems in Popper's proposal (section 2), iii) arguments about Popper's situational analysis and the situational logic of Economics (section 3) and iv) final comments.
\end{abstract}

Key-words: Popper, Karl; Situational analysis; Economics.

JEL B40, B41.

\section{Introdução}

Karl Popper (1902-1994) propôs um método para o crescimento do conhecimento que poderia ser usado tanto nas práticas científicas quanto nas práticas sociais. A ciência preocupada com o conhecimento em si mesmo e o social enquanto busca de formas de ação na sociedade visando a melhores condições de vida para as pessoas aparecem na proposta metodológica popperiana.

(1) Trabalho recebido em julho de 2007 e aprovado em dezembro de 2007.

(2) Professora Doutora do Centro de Educação Superior Norte do Rio Grande do Sul (CESNORS) da Universidade Federal de Santa Maria (UFSM), Campus de Palmeira das Missões, RS, Brasil. E-mail: marin@smail.ufsm.br 
Para o desenvolvimento dessa proposta, Popper tratou primeiramente do que ele considerava serem obstáculos ao crescimento do conhecimento - o positivismo, o psicologismo e o dogmatismo. Num primeiro momento, Popper rejeita o verificacionismo como critério de demarcação entre ciência e não-ciência defendido pelo Círculo de Viena. ${ }^{3}$ Num momento posterior, Popper critica os métodos psicologistas e dogmáticos; o primeiro porque investiga o conhecimento dentro da mente humana, e o segundo, porque acredita que o conhecimento pode ser centralizado numa única mentalidade, sendo certo e único, isto é, não criticável e nem passível de modificações.

Popper apresenta, então, a perspectiva de que a busca e o crescimento do conhecimento seriam resultados de um debate crítico intersubjetivo - o método crítico. Nosso conhecimento é, conforme Popper, ação e reação na intersubjetividade. A supremacia concedida por Popper à investigação científica está relacionada com a noção de que a ciência tem pouca relação com fatores psicológicos ou subjetivos. O conhecimento científico é caracterizado pelo seu método: "a ciência é testável e criticável intersubjetivamente; sua eficácia resulta de um controle racional e objetivo que dispensa convicções subjetivas" (Neiva, 1999, p. 84). A racionalidade decorre dos resultados dos testes, das críticas dos prejuízos, das conjecturas; ela é obtida no campo da intersubjetividade mediante discussão crítica.

No Pós-Escrito da Lógica da Descoberta Científica, Popper (1982) enfatiza que sua visão poderia ser entendida como "falibilismo e abordagem crítica". Por falibilismo se entende que não existe certeza do conhecimento ou verdade, pois todo conhecimento é conjectural e, por abordagem crítica, ele quer demonstrar o que justamente foi denominado de racionalismo crítico. "Todas as teorias científicas estariam abertas ao criticismo, particularmente com referência aos problemas que as teorias em questão estavam designadas a resolver" (Blaug, 1994, p. 112).

O argumento deste artigo é o de que a contribuição de Popper se estende para a aplicação do seu método crítico nas práticas científicas e sociais, com a chamada análise situacional, ou seja, vai além do falsificacionismo e do diálogo socrático, como mostrado nas diferentes interpretações dos metodólogos da economia. ${ }^{4} \mathrm{O}$ objetivo é investigar como a economia tem absorvido a contribuição

(3) O Círculo de Viena foi um grupo de filósofos e cientistas (dentre os quais estavam Rudolf Carnap, Otto Neurath, Herbert Feigl, Philipp Frank, Friedrich Waissman, Hans Hahn), organizado informalmente em Viena à volta da figura de Moritz Schlick (1882-1936). Encontravam-se semanalmente, entre 1922 e finais de 1936, ano em que Schlick foi assassinado por um estudante universitário irado. Muitos membros deixaram a Áustria com a ascendência do partido Nazi, tendo o círculo sido dissolvido em 1936. O seu sistema filosófico ficou conhecido como o "Positivismo Lógico".

(4) Para uma discussão das diferentes interpretações de Popper na economia, ver Marin e Fernandez (2004) e Crespo (2004). 
metodológica de Popper para as chamadas ciências sociais. O interesse está em indagar a existência de uma possível analogia entre o método de Popper para as ciências sociais e a lógica da situação na economia. Popper foi um grande filósofo da ciência que poderia ser identificado com no mínimo três visões metodológicas, e as discussões sobre metodologia em economia ficam incompletas ao ressaltar o falsificacionismo como ponto fundamental e único da contribuição científica e social de Popper.

Com o objetivo de descrever os ensinamentos de Popper também quando se referem às práticas científicas e sociais como resultados de sua ênfase na busca e no crescimento do conhecimento e uma possível semelhança com o método de análise da economia, este artigo apresenta: i) a análise situacional como uma proposta de prática científica e social; ii) as discussões de críticos e comentadores que identificam problemas na filosofia da ciência popperiana; iii) argumentos sobre a análise situacional de Popper e a lógica da situação na economia e iv) as considerações finais.

\section{A Análise Situacional (AS) como prática científica e social}

No que se refere a qual metodologia a ser adotada pelas diferentes ciências, Popper (1945) sugere que tanto as ciências sociais quanto as naturais iniciam e terminam com problemas. Assim, o método científico para as ciências sociais também consiste em procurar tentativas de solução para as situações-problema. ${ }^{5}$ Em ambas (i) as leis naturais, físicas ou psicológicas são conjecturas testáveis, (ii) para haver experimentação e observação são requeridos modelos e condições artificiais, e (iii) existe uma inter-relação complexa entre as suas partes básicas ou fundamentais, seja entre átomos, seja entre indivíduos. Então, “all theoretical or generalizing sciences (...) make use of the same method" (Popper, 1945, p. 78).

Um exemplo ilustra simultaneamente a principal tarefa da ciência e o uso da lógica científica (Popper, 1979, I, p. 349-357). Um cientista social supõe que a realidade em uma determinada comunidade $\mathrm{C}$ é conhecida e pode ser expressa na seguinte afirmação:

(E): “existem 'n' pessoas subnutridas em C".

Este é o explicandum, um enunciado do problema a ser explicado.

O cientista pode conjecturar uma explicação hipotética como se fosse uma condição inicial.

(5) Para Popper, se a ciência e o conhecimento possuem uma origem, eles partem de um problema, e não de percepções, observações ou coleta de dados ou fatos. Contudo, o problema é extraído de uma base que é composta de, pelo menos, uma linguagem e de muitas teorias. A relação lógica entre o problema e a sua base é o que Popper denomina de "situação-problema" (Popper, 1999, p. 160).

Economia e Sociedade, Campinas, v. 17, n. 2 (33), p. 81-102, ago. 2008. 
(I): "a renda baixa nessa comunidade não atrai uma oferta adequada de alimento". determinada.

Isso é parte do explicans: um enunciado da condição explicada e

A lei universal, que pode explicar esse enunciado, é expressa como

(U): "a oferta de alimento segue a existência de renda".

Essa lei impõe a presença de uma condição inicial, no caso, o enunciado (I), e completa o explicans, o qual, junto com a condição inicial, oferece as premissas para deduzir seu explicandum.

Ou seja,

Explicans $(\mathrm{U}+\mathrm{I})$ resulta no Explicandum $(\mathrm{E})$. problema:

Popper distingue, então, três tipos de atitudes em relação a essa situação-

(1) O Teórico, em uma tentativa de refutar a teoria, testará as leis universais e as suas respectivas condições iniciais. Esses testes não dependem da verdade do explicandum. O procedimento é derivar certa conclusão lógica do explicans (uma predição P), a qual é comparada com a situação atual e observável. Se a conclusão é falsificada (P é falsa), o explicans será falso. Por outro lado, a verificação da predição (P é verdadeira) não assegura que o explicans seja verdadeiro. ${ }^{6}$

(2) O Técnico considera a teoria garantida (não a questiona) e tenta resolver o problema prático. $\mathrm{O}$ explicandum é modificado para um conselho "dar alimento para as pessoas". A técnica escolhida seguirá, conseqüentemente, a teoria admitida, em nosso exemplo, "aumentar a renda da comunidade C".

(3) O Historiador tenta descrever a condição específica inicial. Uma determinada condição inicial (I) será uma hipótese histórica, isto é, uma descrição histórica a ser examinada e testada. O historiador estaria interessado em discutir um enunciado do tipo: "a baixa renda nesta comunidade não atrai uma oferta adequada de alimento".

Quando o interesse está em explicar alguma coisa do mundo, as leis universais e as condições iniciais, no mínimo uma ou outra, serão problemáticas. Se o objetivo é a predição, tanto as leis universais quanto as condições iniciais não serão problemáticas, porque o cientista já estará aplicando os resultados científicos

(6) Para uma discussão sobre o falsificacionismo contra verificacionismo, isto é, o problema da demarcação, ver Popper (1983, cap. II). E, para analisar o problema de grau da corroboração, ver Popper (1983, cap. IV). 
da investigação teórica. As leis universais não são usualmente problemáticas fora das ciências teóricas (Popper, 1945, p. 79-84). Se o intuito do cientista é explicar ou predizer um evento local, o problema da fome na comunidade C, ele estudará a lei universal e as condições iniciais conhecidas e envolvidas nesse evento específico. Porém, se o intuito é explicar ou predizer um certo tipo de evento, o problema da fome em qualquer lugar, ele operará com um modelo que representa uma condição inicial típica, dado que "we never have sufficient laws and initial conditions at our disposal" (Popper, 1994, p. 168). Depois de estabelecer a condição inicial típica, o cientista precisa de uma lei universal - uma lei de "animação" - que representa "the way in which the various elements of the model may act upon each other" (Ibid., p. 164).

Popper sugere a análise situacional (AS) como o método que considera as condições iniciais típicas e uma lei universal de animação para analisar conjuntamente as ações humanas e as situações sociais. ${ }^{7} \mathrm{O}$ modelo da AS é mecânico e o princípio de animação é puramente abstrato, ou seja, "a rudimentary working mechanism". A AS leva em consideração os objetos físicos, certos objetivos e o conhecimento ou a informação sobre as instituições sociais que são relevantes para a situação. Em vista disso,

The logical investigation of the methods of economics yields a result which can be applied to all social sciences. This result shows that there is a purely objective method in the social sciences, which may well be called the method of objective understanding, or situational logic (Popper, 1992a, p. 79, grifos no original).

Popper considerou um modelo para a situação social, incluindo a situação institucional na qual a pessoa está inserida e agindo. Segundo Célia Kerstenetzky (2006, p. 5), Popper define situação em termos de determinados propósitos e de condições de conhecimento, sendo sua lógica a orientação da ação levando em conta os objetivos e o conhecimento dos atores envolvidos. Kerstenetzky enfatiza que Popper ainda encapsula propósitos e conhecimento em um contexto de instituições que consistem de todas as realidades sociais do mundo social e que caracterizam a situação e indicam certa lógica de ação, isto é, como é racional agir naquele meio específico: a lógica de poder, a lógica de mercado, etc.

Popper (1966, p. 97) prefere considerar a lógica da situação social, rejeitando a redução a leis gerais da natureza humana, uma vez que "our actions are to very large extension explicable in terms of the situation in which they

(7) Popper (1979, p. 178) prefere a denominação “análise situacional” e não "lógica da situação", pois a última pode sugerir uma teoria determinista da ação humana; e está longe de sua intenção sugerir tal coisa. Popper (1994, nota 1, p. 181) comenta que ele considerou a "logic of choice" de Hayek e a "logic of historical problem situations" para compor a sua "logic of the situation". A "logic of situational choices" não vê "escolha" numa forma determinística. O modelo explica a racionalidade da ação do indivíduo. Porém, tais modelos "are the testable hypotheses of the social sciences; and those models that are 'singular', more specially, are the (in principle testable) singular hypotheses of history" (Popper, 1992b, p. 118). 
occur'. Ele não nega o papel dos aspectos psicológicos (tais como os motivos), apenas argumenta a impossibilidade de incluir todos eles na descrição da situação na qual a pessoa se encontra. Além disso,

... when we speak of 'rational behavior' or of 'irrational behavior' then we mean behavior which is, or which is not, in accordance with the logic of situation. In fact, the psychological analysis of an action in terms of its (rational or irrational) motives presupposes - as has been pointed out by Max Weber - that we have previously developed some standard of what is to be considered as rational in the situation in question (Popper, 1966, p .97).

O método da AS utiliza o princípio de racionalidade - "the various persons or agents involved act adequately, or appropriately - that is to say, in accordance with the situation" - como uma lei de animação (Popper, 1994, p. 169). Esse princípio é um resultado do modelo, seu subproduto, não é uma teoria explanatória empírica, como são os modelos; é somente um elemento do método geral da AS (Ibid., p. 171-172). Segundo Kerstenetzky (2006, p. 6) é a partir da compreensão da situação que existe a possibilidade de formar uma idéia sobre o que é racional fazer naquele contexto e, assim, o princípio de racionalidade surge como um princípio normativo contextual. Além disso, Popper destaca as diferenças pessoais não somente em termos de conhecimentos ou habilidades, mas também ao avaliar e entender a situação. Algumas pessoas agirão apropriadamente com a situação e outras não, isto é, "the rationality principle is not universally true as a description of our ways of acting" (Popper, 1994, p. 183, nota 19).

Popper conecta, ainda, a AS com a discussão crítica de teorias - o método crítico; é possível discutir criticamente os modelos como simplificações da realidade. Não é possível assegurar qual modelo seria mais adequado, mas podemos escolher, entre aqueles em competição, o que se aproxima da verdade. Uma boa política é o teste do modelo, e não do princípio de racionalidade, pois o modelo é "far more interesting and informative, and far better testable, than the principle of the adequacy of our actions" (Popper, 1994, p. 178).

A AS, além de ser uma prática científica para as ciências sociais, pode ser entendida também como um meio para a prática da engenharia social com o objetivo de reformas sociais. Kerstenetzky (2006, p. 5) ressalta que a intenção de Popper ao conhecer o mundo social está no interesse em aceitar as condições de possibilidade da reforma social, da mudança intencional, em busca de um mundo melhor. É com base nessa intenção de Popper de usar a AS como caminho para a mudança social que este artigo destaca a AS como uma prática científica e social na filosofia da ciência de Popper. Para melhor explicitar esse argumento, é preciso esclarecer o posicionamento de Popper sobre o que poderia ser entendido como engenharia social. 
Para Popper (1944, p. 130-131; 1985, p. 313) é difícil estabelecer uma relação entre um planejamento holista, que tem um ponto de partida certo e único, e o método científico, que tem como base a falibilidade de nosso conhecimento e a possibilidade de desenvolvimento de um debate crítico. Para entender o significado dessa dificuldade relacionada com a epistemologia e com a prática social é necessário compreender que Popper acredita na possibilidade de realização de reformas sociais - a engenharia social. Essa engenharia social pode ser executada através da tecnologia social, isto é, uma forma modificada de conhecimento e mais modesta do que o conhecimento certo. A tecnologia social gradual que Popper (1957, p. 158) sugere está baseada em instituições simples, tais como o cuidado com a saúde, o seguro-desemprego e a reforma educacional.

Popper (1944, p. 122-123) argumenta que a principal tarefa dos engenheiros sociais é delinear as instituições sociais, que seriam consideradas por um ponto de vista funcional, isto é, como meios para conseguir determinados fins, mas avaliadas de acordo com a sua adequação, eficiência e simplicidade para alcançá-los. Porém, Popper (1957, p. 24) ressalta que essas instituições não podem ser consideradas apenas como instrumentos mecânicos; elas se modificam de forma similar ao crescimento dos organismos, ou seja, apresentam mecanismos, não previstos em sua origem, de seleção e adaptação ao ambiente. Além disso, os engenheiros sociais compreendem a tecnologia social como a base científica para a política ou ação social e para a mutabilidade das instituições.

Scientific method in politics means that the great art of convincing ourselves that we have not made mistakes, of ignoring them, of hiding them, and of blaming others for them, is replaced by the greater art of accepting the responsibility for them of trying to learn from them, and of applying this knowledge so that we may avoid them in the future (Popper, 1944, p. 131).

Popper trata, portanto, de questões éticas quando defende a possibilidade de reformas sociais através da tecnologia social gradual. Ele assume que uma luta sistemática contra o sofrimento, a miséria e a injustiça econômica e social é mais fácil de ser compreendida por um grande número de pessoas do que uma luta para estabelecer alguma sociedade ideal. Popper não entendia a intervenção do Estado como indefensável em razão de nosso conhecimento limitado. Pelo contrário, ele acreditava na possibilidade de uma intervenção através da tecnologia social gradual que permitisse a observação dos acontecimentos inesperados e sua possível correção. Ou seja, que fosse adotado o método científico ancorado na AS nas ações sociais de forma que favorecesse o crescimento do conhecimento com a aceitação de nosso conhecimento limitado e incerto.

Os planos graduais permitem reajustamentos e condições realistas para a condução de experimentos que podem ser repetidos "without revolutionizing the 
whole society" (Popper, 1957, p. 162). A tecnologia social gradual pode fazer com que os políticos observem e aprendam com seus próprios erros.

(...) politicians begin to look out for their own mistakes instead of trying to explain them away and to prove that they have always been right. (...) This - and not Utopian planning or historical prophecy - would mean the introduction of scientific method into politics, since the whole secret of scientific method is a readiness to learn from mistakes.

(...)

Politics, I demand, must uphold equalitarian and individualistic principles; dreams of beauty have to submit to the necessity of helping men in distress, and men who suffer injustice; and to the necessity of constructing institutions to serve such purposes (Popper, 1957, p. 163-165).

Popper conecta seu pensamento social e político com seu método científico, uma vez que a tecnologia social gradual com o suporte da AS representa uma abordagem racional e crítica para a conduta política e a ação social. A engenharia social estaria ancorada na AS, que segundo Kerstenetzky (2006, p. 5), permite a reconstrução racional e teórica em que uma determinada situação é demarcada e a sua lógica, articulada. Com base nisso que Popper defendia que a tarefa das ciências sociais é descobrir as dificuldades que atrapalham a ação social, ou seja, compreender a resistência do mundo social aos nossos esforços de modificá-lo.

A proposta científica e social na forma da AS foi criticada por apresentar certa inconsistência com a lógica da pesquisa científica de Popper. Porém, para além da discussão da possível incoerência entre a proposta científica e social e a lógica da pesquisa científica, está a questão de qual teria sido a contribuição filosófico-metodológica de Popper na forma da AS para a economia. Antes de ser discutido o método de Popper para as ciências sociais e sua analogia com a prática científica e social em economia, serão apresentadas algumas discussões sobre a AS, entendida como um caminho para a ação social através da engenharia social.

\section{A Análise Situacional (AS) vs. A Lógica da Pesquisa Científica}

Para Bruce Caldwell (1991, p. 13), o objetivo do método da AS é estudar as repercussões sociais não intencionais de ações humanas intencionais, podendo ser o único método de exposição das ciências sociais. A tarefa das ciências sociais não é profetizar sobre problemas da sociedade. ${ }^{8}$ Contudo, para Caldwell, o estabelecimento do princípio racional no lugar das leis universais é problemático. Caldwell sugere um "marco zero" - o postulado de que os agentes atuam apropriadamente para suas situações -, como na teoria microeconômica

(8) O que, por sinal, é um dos temas reiterados na obra de Popper, destacando-se a esse respeito "A Miséria do Historicismo", no qual Popper questiona frontalmente a possibilidade de se fazer grandes previsões em ciências sociais. 
tradicional. Trata-se de um princípio metafísico que não é verificável, nem falsificável, tampouco refutável empiricamente. ${ }^{9}$ Portanto, igualmente ao caso das leis universais que estimulam modelos na ciência natural, o princípio racional anima modelos nas ciências sociais e, conseqüentemente, na ciência econômica. Caldwell (1998) ressalta que o emprego da AS na economia mostra dois problemas. Primeiro, ele aponta uma incoerência entre os métodos defendidos por Popper para as ciências naturais e sociais, uma vez que o princípio de racionalidade da AS seria imune à falsificação (esta crítica também é formulada por Hands, 1992). Segundo, a natureza do princípio de racionalidade é vaga (Caldwell, 1991; 1998). ${ }^{10}$

Essa crítica mostra uma contradição entre o método do falsificacionismo presente na lógica da pesquisa científica de Popper dos anos 1940 e a proposta da AS e seu princípio de animação apresentada nos anos 1960 para ser o método das ciências sociais. Uma das críticas que surge com essa proposta de método objetivo para as ciências sociais é a sua possível contradição com o argumento do racionalismo crítico existente na filosofia da ciência popperiana, inclusive na proposta do falsificacionismo como um critério de ajuizar as teorias empíricas. Ao enfatizar que é o modelo da AS, e não o princípio de racionalidade, que deveria ser criticado, Popper parece imunizar esse princípio de qualquer crítica. A fixação de um princípio permite resultados então considerados científicos. Se tal princípio resultar num rico conteúdo, próprio para a testabilidade, a falsificação e a refutabilidade, pode ser prontamente aceito como racional. Porém, esse racional não é obtido dos dados observáveis e experimentáveis (do indutivismo), mas do racionalismo crítico. Tendo isso em vista, o princípio de animação da AS precisa ser qualificado; é necessário discutir a distinção de, por um lado, a racionalidade proposta por Popper, que é a capacidade de crítica - o racionalismo crítico -, e, por outro lado, o princípio de racionalidade, que é apenas um subproduto da AS.

O método da AS de Popper deve ser entendido como um modelo explicativo para as ciências sociais que considera os indivíduos e os seus ambientes institucionais. Esse modelo analisa a situação dos indivíduos, e pode ser compreendido como uma tentativa de solução para os problemas sociais. Para o seu desenvolvimento, Popper sugere o princípio de racionalidade, salientando que

(9) Em termos simples, enunciados metafísicos seriam proposições filosóficas que não podem ser empiricamente testadas. O termo "Metafísica", do grego tà metà tà physiká - "os (tratados) depois da física" -, foi utilizado para classificar a obra de Aristóteles, significando depois, para os escolásticos medievais, "estudo ou ciência daquilo que transcende o físico ou natural" (Dicionário Houaiss da Língua Portuguesa). Refere-se, ainda, ao campo da Filosofia que trata dos questionamentos acerca dos primeiros princípios ou sobre a natureza do "ser".

(10) Para uma discussão do "princípio de racionalidade" usado na economia, ver Lagueux (1997). Ele destaca, através de uma análise histórica do pensamento econômico, quando foi que tal princípio começou a ter um papel fundamental na economia. Alternativamente, para uma exposição sobre Popper e o princípio de racionalidade como um princípio de animação, ver Lagueux (2002). 
ele seria apenas um mecanismo para animar o modelo explicativo, e não algum princípio da atitude crítica, que é o que caracteriza o racionalismo crítico.

Chalmers (1985) entende que a sociologia também requer que a pessoa aja de uma forma mais ou menos apropriada com a situação, mas "the reductive individualism is much stronger a position than is needed to combat holism". Para Chalmers (1985, p. 73-87), a recomendação de Popper de reduzir a sociologia ao individualismo é problemática, e sugere que é possível depreender uma concepção sociológica, sem o viés individualista, na proposta da AS, uma vez que ela considera as situações sociais, inclui as conseqüências não intencionais e rejeita a teoria conspiratória da sociedade. Apesar de bicicletas demandarem a ação humana, uma explicação do seu funcionamento não pode ser reduzida ao comportamento e ações humanas (Chalmers, 1985, p. 82). Chalmers propõe, então, um princípio de animação mais fraco: "If a social situation is to function then some humans must do what is necessary to make it function" (Ibid., p. 84).

Para Chalmers, esse princípio de racionalidade mais fraco mantém uma sociologia autônoma e compatível com a posição não holista de Popper. Chalmers enfatiza a situação social, evitando uma aproximação da interpretação do princípio de racionalidade com o individualismo problemático e reducionista da economia tradicional. A análise de Chalmers representa uma demarcação na investigação científica e filosófica sobre a "racionalidade". De um lado, existem os defensores da racionalidade individual, entre eles os economistas neoclássicos, os quais advogam o fortalecimento do princípio de racionalidade. De outro lado, existe uma ênfase na autonomia da sociologia ao propor um princípio de racionalidade mais fraco, como insiste Chalmers, o que parece estar próximo da visão da economia institucional.

Kerstenetzky (2006, p. 6-7) destaca a distinção entre duas possibilidades para o princípio de racionalidade. A primeira é ontologicamente individualista um ator que possui propósitos que deseja realizar e que age em conformidade com a situação para atingi-los. Seria necessário, então, que a explicação da ação social fosse em termos de propósitos individuais e restrições, dentro de contextos diversos, mais econômicos ou mais sociológicos. A segunda é metodologicamente individualista - observamos atores interagindo e imputamos intencionalidade e racionalidade situacional aos atores a partir da verificação da conformidade entre suas ações e as regras sociais prevalecentes naquela situação. A visão de Chalmers parece se assemelhar à segunda possibilidade no sentido de que o princípio de racionalidade não é necessariamente indicação de aceitação da racionalidade no sentido de escolha racional ou de comportamento otimizador da economia tradicional. 
As interpretações anteriores para o princípio de racionalidade parecem estar de acordo com o que Popper propôs na AS, porque seu interesse estava num método para a prática científica em ciências sociais, que ao mesmo tempo pudesse servir de base para as ações sociais. Para que esse método pudesse servir de suporte para as reformas sociais, Popper utilizou o princípio de que as pessoas agem conforme as situações apresentadas sem esquecer a influência das diferentes instituições. Esse agir conforme o contexto social apresentado imprime, no entanto, uma conotação que pode ser entendida mais como metodológica do que ontológica ao princípio de racionalidade usado na AS. ${ }^{11}$

Popper, entretanto, não concordaria com a contradição levantada por Caldwell, porque o método científico das ciências naturais e sociais é o método de tentativa e eliminação de erros baseado no racionalismo crítico, cujo falsificacionismo é apenas parte do processo. Popper enfatiza que sua proposta de AS está ligada com o método crítico, uma vez que o modelo explicativo é que deverá ser alvo de críticas por ser mais interessante do que o princípio de racionalidade, em termos de explicação dos fenômenos sociais e do crescimento do conhecimento. Popper não imuniza o princípio de racionalidade; apenas alega que o mais importante é a crítica do modelo explicativo e não do seu mecanismo de animação. O princípio de racionalidade é definido como apenas parte do modelo explicativo e não deve ser confundido com a racionalidade no sentido de atitude crítica. A natureza do princípio de racionalidade é apenas mecânica e, por isso, sem muita importância para o crescimento do nosso conhecimento.

O "princípio de racionalidade" na AS seria somente um subproduto, diferindo da racionalidade no sentido de atitude crítica ou de comportamento maximizador usado na economia tradicional. É mais o modelo que define a "racionalidade" do que a análise da racionalidade individual que compõe o modelo (Popper, 1994, p. 154, 181). Para Popper, "racionalidade" significa atitude crítica na presença de problemas e de suas tentativas de solução. Ele enfatiza que uma pessoa com objetivos e conhecimento é colocada em alguma situação típica e abstrata e, para animar esse modelo, assume-se que ela agirá apropriadamente conforme a situação na qual se encontra. Isso é somente uma lei de animação "which is clearly an 'almost empty' principle" (Popper, 1979, p. 169). Para Popper, uma análise restrita à racionalidade do indivíduo - sem considerar a sua situação e, em conseqüência, sem adotar um princípio de racionalidade - pode considerar apenas os aspectos psicológicos envolvidos. O problema surge quando esses aspectos psicológicos são considerados como os princípios de análise autoritários

(11) Para uma discussão sobre a ontologia na proposta da AS de Popper, ver Oakley (2002). 
e reducionistas, como, por exemplo, na economia, a hipótese do comportamento maximizador da utilidade ou do lucro. ${ }^{12}$

A ênfase de Popper no racionalismo crítico reflete um entendimento que se situa entre um princípio metodológico e uma definição de racionalidade humana. O princípio de racionalidade leva-nos a perceber que Popper está interessado em uma determinada situação, entendida como um modelo e não como uma ação individual ou uma definição de racionalidade individual. O princípio de racionalidade da AS não é uma concepção de racionalidade do indivíduo. A AS é um método de explicação que usa um princípio de racionalidade mecânico, mas que não é imunizado das críticas. Esse método de Popper para as ciências sociais está intrinsecamente ligado ao seu método científico que tem como fundamento o racionalismo crítico, que, como atitude crítica, não deve ser confundido com o princípio de racionalidade entendido como mecanismo animador.

Bartley (citado por Artigas, 1999, p. 19), entretanto, questiona o racionalismo crítico de Popper, enfatizando que esse tipo de racionalismo deve, também, ser criticado. Ele requer uma "teoria da racionalidade" para ultrapassar a simples "fé na razão" manifestada por Popper. Porém, o racionalismo crítico de Popper não é uma tese, nem uma teoria, nem um dogma; é uma atitude de um indivíduo que quer conhecer (Artigas, 1999, p. 30).

As to the rationality of science, this is simply the rationality of critical discussion. Indeed, there is nothing, I think, which can better explain the somewhat abstract idea of rationality than the example of a well-conducted critical discussion. And a critical discussion is well-conducted if it is entirely devoted to one aim: to find a flaw in the claim that a certain theory presents a solution to a certain problem. The scientists participating in the critical discussion constantly try to refute the theory, or at least its claim that it can solve its problem (Popper, 1994, p. 160).

Popper defende que a atitude crítica é o ponto decisivo da racionalidade; é a capacidade de maior importância. Popper (1966, p. 224-225) é antiessencialista e não conjectura o que é "racionalidade"; prefere associá-la à capacidade de adotar uma atitude racional de prontidão para escutar os argumentos críticos (à Sócrates) e para aprender com a experiência. Para Popper, se estamos aprendendo com a experiência, isso significa apenas que algumas de nossas teorias podem ser falsas. A teoria do conhecimento de Popper é socrática, uma vez que a ciência pode ser "a learning enterprise whose sole objective is to find errors in our understanding" (Boland, 1998a, p. 167).

(12) Para Latsis (1972), o programa neoclássico de "determinismo situacional" na economia mostrou que o princípio de racionalidade estava sendo trivial porque o comportamento humano (maximização de lucro ou outros) está mais do que institucionalizado nas interações (social, física e psicológica) complexas sob condições perfeitamente competitivas. A situação é outra com a "emergência do behaviorismo econômico", quando foi destacada a importância da natureza dos agentes decision-making sob condições imperfeitas (risco, incerteza e ignorância). 
Alguns dos interpretadores de Popper apresentados aqui mostram uma possível tensão entre a adoção do racionalismo crítico, que é o pano de fundo não apenas do falsificacionismo, mas de sua filosofia da ciência, e a AS. Para Hands e Caldwell, no que se refere às ciências sociais, Popper elabora o método da AS como sendo o método compreensivo-objetivo para tais ciências. Nesse novo método, Popper estabeleceu o princípio de racionalidade para excluir toda e qualquer característica psicológica das análises referentes às diferentes situações dos indivíduos. O princípio de racionalidade, despojado de meios psicológicos e de características empiristas, foi criado por Popper para animar os modelos nas ciências sociais. Então, o Popper falsificacionista, para Hands e Caldwell, era incompatível com o da AS. Para Caldwell, o racionalismo crítico foi a maneira encontrada por Popper para burlar esse problema. Esses metodólogos estão relacionando a economia apenas com o falsificacionismo, o que mostra um entendimento da economia como uma ciência sujeita a testes empíricos. Por essa razão, concluem que esta visão falha, uma vez que seus enunciados não são falsificáveis. Porém, a incompatibilidade entre o Popper falsificacionista e o Popper da AS, destacada por Hands e Caldwell, não aparece como preocupação de Popper e os metodólogos estariam atacando um problema inexistente.

No artigo $O$ princípio de racionalidade, publicado pela primeira vez em 1967, Popper estabelecia que as ciências sociais operassem com o método de construir situações em condições típicas. Por meio da AS, as situações sociais típicas são transformadas em modelos. O erro, segundo Popper, está em animar o modelo social com as leis da psicologia humana. Então, ele sugere a fixação de um princípio de racionalidade: "os agentes sempre atuam de maneira apropriada à situação em que se encontram" (Popper, 1985, p. 387). Mas "utilizamos o princípio de racionalidade simplesmente como uma boa aproximação à verdade, reconhecendo que não é verdadeiro, senão falso" (Ibid., p. 390).

A proposta de Popper é, por ela mesma, uma teoria da racionalidade científico-social, e não uma proposição de um princípio de racionalidade individual. Popper adotou o individualismo metodológico e um princípio de racionalidade fraco na AS. Isso inclui a ação do indivíduo - como um elemento operativo - na descrição e argumentação em ciências sociais. A sociedade é composta de indivíduos concretos e anônimos, e a teoria social da razão é interpessoal (Popper, 1966, p. 226). A epistemologia de Popper (1957, p. 256; 1966, p. 226, 246, 385; 1968b, p. 8), portanto, considera cada indivíduo como um fim em si mesmo e que pensa por si próprio.

No entanto, o cientista social não pode conceder autoridade aos sentidos ou ao intelecto, ao subjetivismo ou à arbitrariedade individual. $\mathrm{O}$ indivíduo, bem como sua conduta e ação, é único e não pode ser plenamente racionalizado. Popper reconheceu as situações sociais autônomas e independentes da liberdade 
humana, as quais criam dificuldades para a aceitação do princípio de racionalidade interpretado unicamente como individualismo ontológico, uma vez que a AS abrange a avaliação moral, um ambiente social para o debate crítico e limites para a arbitrariedade.

Para além do possível problema com a falta de coerência entre a lógica da pesquisa científica e a AS em Popper, existe a questão de como a metodologia da economia absorveu a proposta popperiana da AS. É interessante notar que foi a partir da prática científica em economia que Popper desenvolveu sua AS para, a partir dela, buscar a explicação, e não a previsão, das diferentes situações sociais, com o objetivo das reformas sociais. Os economistas teriam retido a idéia da AS de Popper como uma forma objetiva de explicação das situações sociais nas quais os indivíduos estão inseridos como o método mais próximo das chamadas ciências sociais?

\section{A Análise Situacional e a economia}

Para Popper (1992a), a economia política caracteriza-se como exemplo de um método para a investigação lógica das ciências sociais, com base no princípio de racionalidade e dentro da AS. Porém, a AS não pode ser vista apenas como o único método das ciências sociais. Os princípios e pressupostos desta estão situados em uma lógica mais abrangente, a que inclui também as ciências naturais, qual seja a metodologia das ciências como sendo o método da discussão crítica em razão do nosso conhecimento falível. Diante disso, o falsificacionismo caracterizase como um critério forte para ajuizar se uma teoria é testável e aceitável como científica.

As análises desenvolvidas na microeconomia tradicional são tomadas como exemplos de aplicação do método de Popper para as ciências sociais, uma vez que operam com modelos que combinam uma determinada lógica da situação e o princípio de racionalidade. Hands (1992) constata a aplicabilidade da AS na economia, afirmando que se trata do método da microeconomia (e também da macroeconomia baseada em microfundamentos).

A análise situacional é o que em economia se conhece por conceito de escolha racional, isto é, a visão de que o comportamento econômico é simplesmente o comportamento maximizador individual sujeito a restrições, e na verdade Popper declarou a 'análise situacional' ser uma generalização do método da análise econômica (Blaug, 1994, p. 112).

Segundo a AS, preferências, tecnologias e restrições (preços, renda, etc.) mostram a situação do agente e sua motivação (maximização da utilidade). Essa situação é analisada segundo a dedução de um comportamento (compra mais ou menos, produz mais ou menos, etc.) que, quando apropriado, é matematizável na teoria econômica. Finalmente, fixa-se o princípio racional, segundo o qual os 
agentes atuam apropriadamente (racionalmente), dadas as situações analisadas. Esse esquema lógico parece ser o da AS.

Porém, Hands (1992) verifica um paradoxo no fato de a metodologia econômica ter focalizado mais a visão falsificacionista do que a AS. Mas a AS seria exemplificada através das análises feitas na microeconomia, eis que baseada num princípio de racionalidade estabelecido (os indivíduos agem com uma razão econômica), em uma dada situação social.

Para responder ao questionamento de Hands sobre um possível desconhecimento por parte dos economistas da proposta da AS, destaca-se o seguinte:

\section{Postmodernism?}

... social scientists who tune into philosophy to get the latest ideas hear about logical positivism; hear about Kuhn, Feyrabend, and Lakatos; and hear about Postmodernism, but they do not hear about Popper, expect insofar as his ideas are misreported by the above. However, the logic of doing social science is much that the situational logic is taken for granted, used without much awareness that it is articulated and endorsed by one of the century's greatest philosophers (Jarvie, 1998, p. 378).

Além disso, Notturno (1998) argumenta que a proposta de Popper pode não ter tido o reconhecimento que seria suposto ter dentro da economia, porque ela não estaria destinada, como ocorre com os modelos econômicos, a fazer previsões. ${ }^{13}$ Muitos economistas esperam usar seus modelos para predizer o futuro e isso, talvez, seja uma das razões de o método da AS e o princípio de racionalidade de Popper não serem tão atrativos. "Popper not only thought that the purpose of models and situational analysis and the rationality principle is to help us to explain and understand events in terms of human action and social situations; he also explicitly denied that the task of social science is to make predictions or prophecies about the future" (Notturno, 1998, p. 416).

Segundo Kerstenetzky (2006), a lógica situacional está presente nas análises da economia e pode ser entendida como um ingrediente metodológico comum que permite a integração da explicação econômica e sociológica no continente mais abrangente das ciências sociais. Para ele, existem várias lógicas situacionais na economia que servem de integração da economia com a sociologia. Porém, é preciso ressaltar que, para Kerstenetzky (2006), a teoria da escolha racional, como desenvolvida por Gary Becker nos anos 1980, foi formulada como lógica da situação, uma lógica econômica que explicaria o comportamento

(13) Uma das grandes vantagens da economia neoclássica é a precisão de suas predições. Conhecendo a função de custo de cada firma e a função de demanda para a indústria, o analista pode predizer qual será a produção de cada firma, e então, qual será o preço do produto, assumindo que cada firma maximiza seu lucro diante da escolha da produção (Mueller, 2004, p. 62). 
humano em uma gama ilimitada de atividades sociais. No entanto, como pura lógica de ação, esse modelo não é o único; existem outras lógicas da ação humana que não se enquadram na definição de Becker de ajustamento de meios a fins. A teoria da escolha racional aparece, segundo Kerstenetzky (2006), como um caso particular em um conjunto mais geral de lógicas situacionais que nos possibilitam identificar a racionalidade no agir humano em diferentes situações e com orientações diversas. "A lógica situacional LS resguarda o pluralismo inerente à idéia de racionalidade humana, cara ao cientista social em seus esforços de compreender os fatos sociais recorrendo igualmente à racionalidade" (Kerstenetzky, 2006, p. 11). ${ }^{14}$

Matzner e Jarvie (1998) ressaltam que foi Popper (anos 1960) e não Gary Becker (anos 1970) a primeira pessoa a formular um programa para estender a lógica da economia às ciências sociais não econômicas. Becker propôs uma versão muito forte da escolha racional e resumiu sua mensagem básica na seguinte passagem: "The combined assumptions of maximizing behavior, market equilibrium, and stable preferences, used relentlessly and unflinchingly, form the heart of the economics approach as I see it" (Becker, 1976, p. 5 apud Matzner; Jarvie). Pode ser acrescentado ainda que instituições não desempenham qualquer papel no argumento de Becker e que é suficiente que tenhamos apenas um ator racional que maximiza e que tem preferências estáveis.

Para Matzner e Jarvie (1998), Popper tem um posicionamento diametralmente oposto ao de Becker. As preferências estáveis não são mencionadas em seu artigo; elas são, quando muito, decorrências em sua análise. A maximização é discutida apenas em notas de rodapés, mas não quando Popper discute as ciências sociais não econômicas. O foco de Popper não está no ator individual, mas na situação; além disso, a situação contém diversas instituições que afetam diretamente o comportamento do indivíduo. Popper, em outras palavras, está divulgando um tipo de análise "econômico-social" mais do que uma forma econômica apenas. "Indeed, if one were to take situational logic and apply it to mainstream economics, the latter would change quite a bit!” (Ibid., p. 337).

A AS é coerente com uma leitura individualista, mas limitada pelas instituições e tradições no sentido de que as decisões individuais são permeadas por valores sociais e culturais que limitam a racionalidade estritamente econômica

(14) Como exemplo, a análise de Amartya Sen sobre a ação do indivíduo com base em outros motivos e razões além da busca da maximização guiada pelo interesse próprio, ou seja, existe uma lógica de ação mais ampla do que apenas a busca da escolha consistente e ótima. Sen (1977, 1987, 1998, 1999, 2002) critica as diferentes interpretações da racionalidade na economia por refletirem uma representação equivocada do comportamento humano, especialmente no que diz respeito às decisões econômicas. $\mathrm{O}$ argumento principal de Sen é que alguns motivos, como o que ele define como compromisso ou comprometimento - the concern for other people's situation even when this would lead to a predictable worst situation for the person so concerned-, deveriam ser parte do comportamento econômico. 
baseada nos fins últimos. A AS está presente na economia, mas o princípio de racionalidade não é o que foi sugerido por Popper quando ele estabelece que os indivíduos agem conforme a situação. $\mathrm{O}$ agir conforme a situação implica que a ação humana dependerá do contexto apresentado; e esse contexto nem sempre é o de ação com vistas à maximização dos resultados econômicos. O agir humano pode ser racional, no sentido de não estúpido, se em conformidade com a lógica da situação, e não apenas quando voltado à relação entre meios e fins. A lógica da situação em si como é apresentada na economia parece não ser a mesma preconizada por Popper.

Como ressalta Lawrence Boland (1998b), uma forma menos ambiciosa de explicação neoclássica poderia reconhecer que, na mente do tomador de decisão, existem variáveis e restrições que são não individualistas e não naturais. "Thus, any explanation of the logic of the situation must also specify how the individual views the logic of the situation that he or she faces. It is virtually impossible to conceive of a decision maker who is not facing or including macroeconomic variables in the logic of his or her situation" (Ibid., p. 520). Para Boland (1998a, p. 32), os indivíduos, na metodologia individualista de Popper, são identificáveis com as situações-problema e não com os seus estados (ou predisposições) psicológicos. ${ }^{15} \mathrm{O}$ tomador de decisão da economia tradicional é transformado em um solucionador de problemas com objetivos que podem não ser psicologicamente dados, isto é, depender única e exclusivamente das suas preferências. Isso difere do individualismo metodológico da economia tradicional, o qual acredita que os estados psicológicos do indivíduo, identificados apenas a partir de sua funçãoutilidade, constituem a única variável que caracterizaria a abordagem individualista.

Boland destaca, também, que a pressuposição de um tomador de decisão racional baseado no seu estado psicológico, o qual se refere à racionalidade como sendo uma predisposição psicológica (não uma psicologia humana), restringe a lista de variáveis não individualistas aceitáveis. ${ }^{16} \mathrm{~A}$ implicação dessa restrição para as teorias econômicas tradicionais do comportamento humano é a especificação de uma concepção apropriada da relação entre instituições e indivíduos (Boland, 1998a, p. 31). Para Boland, a economia tradicional acredita

(15) Ver Barbieri (2006) para uma aplicação das idéias de Popper sobre o crescimento do conhecimento na compreensão do conhecimento dos empresários, entendidos como formuladores de teorias que são constantemente criticadas e não como agentes passivos que maximizam funções já delineadas na teoria convencional.

(16) Boland (1987) enfatiza que um indivíduo, cuja função-utilidade é determinada por convenções sociais, não é menos capaz de tomar uma decisão racional do que outro indivíduo cuja função-utilidade é psicologicamente dada. Para ele, uma explicação metodológico-individualista do comportamento de um tomador de decisão racional é uma questão de estabelecer a lógica da situação objetiva do tomador de decisão, e não uma questão de demandar a sua predisposição psicológica. 
que a metodologia está preocupada com as conseqüências elaboradas pelo tomador de decisão racional, enquanto a metodologia de Popper e sua visão alternativa de individualismo estão voltadas para o processo de decisão racional.

Popper rejeitou a identificação de objetivos com o estado psicológico, ou da racionalidade, com a predisposição psicológica (Boland, 1998a, p. 35). Os indivíduos possuem objetivos, mas eles podem não ser psicologicamente dados, isto é, depender unicamente das preferências individuais. Boland enfatiza que as instituições estão entre as variáveis explanatórias, e o individualismo de Popper não é um programa de pesquisa reducionista no sentido de excluir as variáveis que não estritamente relacionadas ao indivíduo tomador de decisão.

Como Noretta Koertge (1985, p. 129-131) afirma, o método da AS supera a base metafísica da ciência social que tem sido polarizada em natureza $v s$. convenção, indivíduo vs. coletivo e racional vs. irracional. Porém, ela argumenta que a falta de congruência entre a situação-problema e sua solução é uma indicação de que o cientista não compreendeu adequadamente as instituições ou episódios existentes. É necessário criar teorias sobre aqueles tipos de fatores que podem ser considerados como relevantes para a análise envolvendo as situaçõesproblema reais na ciência social. Mas essas teorias devem ser criticamente debatidas, comparadas com outras e, se possível, refutadas, porque aprendemos somente com as refutações, a eliminação dos erros e o feedback, ou seja, como a abordagem da falibilidade de Popper nos ensina.

A AS pode ser entendida como uma prática científica na medida em que Popper estava interessado em um método objetivo que pudesse ser usado nas ciências sociais na busca do conhecimento acerca da realidade social a fim de promover as reformas sociais necessárias. Nesse sentido, a AS também pode e deve ser entendida como prática social, uma vez que serve de suporte para o que Popper denominou de engenharia social, que é o aparato metodológico popperiano que possibilita, através das diferentes lógicas situacionais, modificar as instituições visando às reformas sociais. A AS é guiada pelo individualismo metodológico, mas está inserida num contexto de instituições. As diferentes lógicas situacionais limitam as decisões estritamente individuais ao darem margem para as influências sociais e culturais.

Popper propõe a AS como um modelo explicativo dos fenômenos sociais, mas não ultrapassa essa recomendação de construção de um modelo objetivo exposto à crítica e não oferece uma proposta convincente de como incluir as questões morais nesse modelo. 


\section{Considerações finais}

Qual é o objetivo por trás da lógica presente nos modelos econômicos e no método da AS de Popper? No primeiro, o interesse está em prever a situação social a partir de uma racionalidade humana fixada a priori ou em prever a racionalidade humana com a situação (e restrições) fixada? No segundo, é a explicação dos fenômenos sociais a partir da situação na qual o indivíduo está agindo com o interesse nas reformas sociais mais abrangentes ou a explicação da ação fixada à situação?

A AS popperiana tem o propósito de explicar um certo tipo de evento e de ultrapassar a dicotomia indivíduo e sociedade. Para isso se exige um princípio de racionalidade que funcione como um princípio de animação - o indivíduo age de acordo com a situação que lhe é apresentada. Porém, nada é fixado a priori sobre a racionalidade individual, tal como é proposto nos modelos econômicos. O indivíduo age conforme a situação, mas a situação apresentada pode ser, por exemplo, a de atravessar uma avenida movimentada sem ser atingido por um carro. Nesse, e em qualquer caso, os indivíduos racionais, quando inseridos nas diferentes situações, sejam econômicas ou sociais, agirão de acordo com a situação. Se a rua estiver movimentada e o que o indivíduo quer é chegar ao outro lado, ele atravessará a rua sem, por nenhum minuto, agir compelido por seu comportamento maximizador previamente determinado e calculado.

A metodologia da economia parece possuir nuances da proposta da AS de Popper, principalmente a idéia de um princípio animador que funcionasse como uma espécie de mecanismo acionador da mecânica econômica, proporcionando a possibilidade de se fazer previsões na economia. Porém, a idéia da AS de Popper é mais abrangente, porque permite substituir a racionalidade do agente maximizador, que serve de princípio de animação dos modelos econômicos, por outros tipos de racionalidade que melhor refletem a ação conforme a situação. E, por seguir a noção de falibilidade do nosso conhecimento, a AS não pode alicerçar uma forma de garantir a previsão dos fenômenos econômicos ou sociais. Até porque uma previsão no sentido determinístico do termo não estava presente na filosofia da ciência de Popper, mesmo antes da elaboração do que ele denominou de método mais adequado para as ciências sociais. A AS visava, antes, oferecer o modelo explicativo para a ação de engenharia social, revista a cada instante de mudança da situação social envolvida.

A proposta de intervenção social de Popper através da AS mostra que reformas institucionais e sociais são possíveis e podem ser realizadas com planos simples que considerem a situação das pessoas e possibilitem melhoramentos ao longo do seu processo de implementação. Mas o modelo da AS popperiano recebeu críticas e a principal delas é a falta de uma avaliação moral assim como 
Solange Regina Marin

ocorre nos modelos econômicos. Ele não descartava a importância das motivações humanas na avaliação da situação na qual o indivíduo estava agindo, porém alegava que elas seriam tantas e tão diversas que seria difícil elencá-las. Por isso, a exposição da situação em que a pessoa estivesse agindo seria essencial para a explicação.

Contudo, a AS poderia considerar uma avaliação ética e moral para incluir as principais motivações (e razões) das pessoas nas diferentes situações, um estudo que não foi suficientemente abordado por Popper, constituindo uma deficiência de sua abordagem. Para suprir essa falta de argumentação ética e moral, ressalta-se o trabalho de Amartya Sen pela tentativa de unir a análise das diferentes situações econômicas e sociais com a filosofia moral.

De forma resumida, pode-se afirmar que falta coerência entre a lógica da situação estritamente econômica, como apresentada nos diferentes modelos da economia tradicional, e a análise da situação "social-econômica" apresentada por Popper. A análise da situação social-econômica, ao não estar baseada numa única noção de racionalidade individual, poderia ser enriquecida com a tentativa de resgatar a moral para o discurso da economia feita por Amartya Sen.

\section{Referências bibliográficas}

ARTIGAS, Mariano. The ethical nature of Karl Popper's theory of knowledge. New York: Peter Lang, 1999.

BARBIERI, Fabio. Filosofia da ciência como ferramenta microeconômica". Nova Economia, v. 16, n. 31, p. 507-534, 2006.

BLAUG, Mark. Why I am not a constructivist. Confessions of an unrepentant Popperian. In: BACKHOUSE, Roger E. (Ed.). New directions in economic methodology. London: Routledge, 1994. p. 109-136.

[1983]. Metodologia da economia: ou como os economistas explicam. Trad. Afonso Santos Lima. São Paulo: Edusp, 1999.

BOLAND, Lawrence. Individualist economics without psychology. In: Peter Earl (Ed.). Psychological economics: development, tensions, prospects. [s.l.: s.n.], 1987.

Scientific thinking without scientific method: two views of Popper. In: BACKHOUSE, Roger E. (Ed.). New directions in economic methodology. London: Routledge, 1994.

[1982]. The foundations of economic method. Canada: Simon Fraser University, 1998a.

Situational analysis beyond neoclassical economists. Philosophy of the Social Sciences, v. 28, n. 4, p. 515-521, 1998 b.

CALDWELL, Bruce. Clarifying Popper. Journal of Economic Literature, v. 29, n. 1, p. 1-33, 1991. 
CALDWELL, Bruce. Situational analysis. In: DAVIS, John B.; HANDS, D. Wade; MÄKI, Uskali (Ed.). The handbook of economic methodology. USA: E. Elga, 1998.

CHALMERS, A. F. Methodological individualism: an incongruity in Popper's philosophy. In: CURRIE, Gregory; MUSAGRAVE, Alan (Ed.). Popper and the human sciences. Dordrecht: Nijhoff international philosophy series, 1985. v. 19, p. 73-88.

CRESPO, Ricardo. Los tres Popper de la economía. In: CONGRESO Filosófico Internacional Karl Popper: vigencia y transformación de su pensamiento, Facultad de Humanidades y Artes de Rosario (UNR), 3-5 jun. 2004.

FRISBY, David. The Popper-Adorno controversy: the methodological dispute in German sociology. Philosophy of the Social Sciences, v. 2, p. 105-119, 1972.

HANDS, D. Wade. Falsification, situational analysis and scientific research programs: the Popperian tradition in economic methodology. In: DE MARCHI, Neil (Ed.). PostPopperian methodology of economics: recovering practice. Boston: Kluwer Academic Publishers, 1992.

JARVIE, Ian C. Situational logic and its reception. Philosophy of the Social Sciences, v. 28, n. 3, p. 365-380, 1998.

KERSTENETZKY, Célia. A lógica da situação. In: ENCONTRO NACIONAL DE ECONOMIA, 34, Salvador, BA. Disponível em: http://www.anpec.org.br/encontro2006/ artigos/A06A001.pdf. Acesso em: 12 jan. 2006.

KOERTGE, Noretta. Beyond cultural relativism. In: In: CURRIE, Gregory; MUSAGRAVE, Alan (Ed.). Popper and the human sciences. Dordrecht: Nijhoff international philosophy series, 1985. Dordrecht: Nijhoff international philosophy series, 1985. v. 19, p. 121-132.

LAGUEUX, Maurice. The rationality principle and classical economics. In: CONGRESS of History of Economics Society, College of Chalerston, Chalerston, SC, 1997.

Popper and the rationality principle. In: POPPER Centenary Conference, Vienna, 2002. Disponível em: http//www.the-rathouse.com/popconf.html.

LATSIS, Spiro J. Situational determinism in economics. The British Journal for the Philosophy of Science, v. 23, n. 3, p. 207-245, 1972.

MARIN, Solange R.; FERNÁNDEZ, Ramón G. O pensamento de Karl Popper: as diferentes interpretações dos metodólogos da ciência econômica. Análise Econômica, v. 22, n. 41, p. 155-176, 2004.

MATZNER, Egon; JARVIE, Ian C. Introduction to the special issues on situational analysis. Philosophy of the Social Sciences, v. 28, n. 3, p. 333-338, 1998.

MUELLER, Dennis. Models of man: neoclassical, behavioural, and evolutionary. Politics, Philosophy \& Economics, v. 3, p. 59-76, 2004.

NEIVA, Eduardo. O racionalismo crítico de Popper. Rio de Janeiro: Francisco Alves, 1999.

NOTTURNO, Mark. Truth, rationality and the situation. Philosophy of the Social Science, v. 28, n. 3, p. 400-421, 1998. 
Solange Regina Marin

OAKLEY, Allen. Popper's ontology of situated human action. Philosophy of the Social Science, v. 32, p. 455-486, 2002.

POPPER, Karl. The poverty of historicism, II. A Criticism of Historicist Methods. Economica, v. 11, n. 43, p. 119-137, 1944.

. The poverty of historicism, II. Economica, v. 12, n. 46, p. 69-89, 1945.

LTD, 1957. v. I.

[1945]. The open society and its enemies. London: Routledge \& Kegan Paul

[1945]. The open society and its enemies. Princeton and New Jersey: Princeton University Press, 1966. v. II.

[1934]. The logic of scientific discovery. New York: Harper, 1968a.

[1963]. Conjectures and refutations. New York: Harper, 1968b.

Press, 1979.

[1972]. Objective knowledge. An evolutionary approach. Oxford: Clarendon

. Quantum theory and the schism in physics. From the postscript to the logic of scientific discovery. Edited by W.W. Bartley, III. New Jersey: Rowman and Liettlefield, 1982.

Realism and the aim of science. From the postscript to the logic of scientific discovery. Edited by W.W. Bartley, III. New Jersey: Rowman and Liettlefield, 1983.

[1967]. The rationality principle. In: MILLER, David (Ed.). Popper selections. New Jersey: Princeton University Press, 1985.

[1961]. Search of a better world. Lectures and essays from thirty years. London: Routledge, 1992a.

1992b.

[1974]. Unended quest. An intellectual autobiography. London: Routledge,

; NOTTURNO, M. A. (Ed.). The myth of the framework. In defence of science and rationality. London: Routledge, 1994.

[1972]. Conhecimento objetivo. Belo Horizonte: Editora Itatiaia, 1999.

[1963]. Conjectures and refutations. The growth of scientific knowledge. London: Routledge Classics, 2002.

SEN, Amartya. Rational fools: a critique of the behavioral foundations of economic theory. Philosophy and Public Affairs, v. 6, n. 2, p. 317-344, 1977.

. On ethics and economics. New York: Basil Blackwell, 1987.

[1984]. Resources, values and development. Cambridge: Harvard University Press, 1998.

. Development as freedom. New York: Anchor Books, 1999.

University Press, 2002. 